\title{
HUBUNGAN LAMA PENGGUNAAN KONTRASEPSI PIL DENGAN KEJADIAN DEPRESI
}

\author{
The Correlation Between Duration Using Contraceptive Pills and Depression
}

\author{
Fika Aulia \\ Program Studi D3 Kebidanan, Fakultas Keperawatan dan IImu Kesehatan \\ Universitas Muhammadiyah Banjarmasin \\ fikaaulia26@gmail.com
}

\begin{abstract}
ABSTRAK
Depresi dapat disebabkan karena faktor hormonal, misalnya penggunaan kontrasepsi. WHO memperkirakan bahwa depresi akan menjadi penyakit terbesar kedua di dunia pada tahun 2020. Tahun 2017, jumlah akseptor kontrasepsi hormonal di Daerah Istimewa Yogyakarta sebesar 68.861 akseptor (63\%). Kontrasepsi pil memiliki kecenderungan depresi akibat dari efek samping fisik dan psikologis, misalnya gangguan suasana hati. Alasan beberapa wanita menghentikan penggunaan kontrasepsi pil adalah perubahan suasana hati. Depresi pada ibu akan menghasilkan gejala mental dan fisik yang mempengaruhi kualitas dan produktivitas sehingga dapat berefek buruk pada ibu, anak, dan keluarga. Tujuan penelitian ini adalah diketahuinya hubungan lama penggunaan kontrasepsi pil dengan kejadian depresi di wilayah kerja Puskesmas Banguntapan I. Penelitian ini merupakan penelitian kuantitatif dengan pendekatan waktu cross sectional. Teknik pengambilan sampel yaitu purposive sampling. Populasi sebanyak 409 akseptor pil. Besar sampel ditentukan dengan tabel kretji diperoleh 196 sampel. Instrumen penelitian menggunakan kuesioner modifikasi PHQ-9 (Patient Health Questionare-9). Analisa data menggunakan chi-square. Hasil didapatkan nilai $p=0,018$ dan $O R=2,192$ artinya akseptor kontrasepsi pil dengan lama penggunaan >2 tahun memiliki peluang 2,192 kali lebih besar terjadi depresi dibandingkan dengan akseptor pil dengan lama penggunaan $\leq 2$ tahun. Simpulan penelitian didapatkan ada hubungan lama penggunaan kontrasepsi pil dengan kejadian depresi.
\end{abstract}

Kata Kunci

: Lama penggunaan, Kontrasepsi, Pil, Depresi

\section{ABSTRACT}

Depression can be caused by hormonal factors, such as the use of contraception. The WHO estimates that depression will become a disease with the world's second largest burden in 2020. In 2017, the number of hormonal contraceptive acceptors in Yogyakarta reached 68.861 acceptors (63\%). Contraception pills have a tendency to depression due to physical and psychological side effects, such as mood disorders. The reason some women stop using contraceptive pills is a change in mood. Depression in the mother will produce mental and physical symptoms that affect quality and productivity so that it can have a negative effect on mother, child and family. The purpose of this study was to determine the correlation between using contraceptive pills use and the tendency of depression level in the working area of Banguntapan I Primary Health Center in 2018. This study applied a quantitative study with a cross sectional time approach. The sampling technique used purposive sampling. The study population was 409 pill acceptors. The sample size was determined by the kretji table, which consisted of 196 samples. The research instrument used a modified PHQ-9 questionnaire (Patient Health Questionare-9). Data analysis employed chi-square. The results obtained $p=0.018$ and $O R=2.192$ meaning that the pill acceptors with a duration of use $>2$ years had a chance of 2.192 times greater depression compared to duration of use $\leq 2$ years. The conclusions of the study showed that there was correlation between duration of using contraceptive pills and the tendency of depression.

\section{Keywords : : Duration of Use, Contraception, Pills, Depression}




\section{PENDAHULUAN}

sosial dengan efek buruk pada ibu, anak, dan keluarga.

Tiga besar peringkat penggunaan kontrasepsi pil

Depresi dapat disebabkan karena Faktor hormonal, misalnya pada penggunaan kontrasepsi hormonal. Kontrasepsi hormonal merupakan kontrasepsi yang banyak dipilih oleh masyarakat di Indonesia. Berdasarkan hasil Susenas (2015) menunjukkan bahwa sebagian besar Pasangan Usia Subur peserta KB di Indonesia masih mengandalkan kontrasepsi hormonal yaitu suntikan $(59,57 \%)$ dan pil $(20,71 \%)$ dari total pengguna KB. Hasil Survei Demografi Kesehatan Indonesia (2012) menyebutkan sebanyak $62 \%$ wanita kawin menggunakan kontrasepsi, $58 \%$ menggunakan metode modern, dan $4 \%$ menggunakan metode tradisional. Kontrasepsi suntik menjadi metode kontrasepsi yang paling banyak digunakan, diikuti oleh pil (masing-masing sebesar $32 \%$ dan $14 \%)$.

Kontrasepsi pil memiliki efek samping mual, muntah, perdarahan bercak, peningkatan berat badan, dan gangguan suasana hati atau depresi. Depresi dapat disebabkan oleh penggunaan alat kontrasepsi terutama alat kontrasepsi hormonal yang menyebabkan ketidakseimbangan hormon dalam tubuh. Efek samping yang ditimbulkan merupakan hasil dari estrogen dan progesterone sintetik yang terdapat di dalam kontrasepsi. Sebanyak $51 \%$ wanita dilaporkan memiliki setidaknya satu efek samping saat menggunakan kontrasepsi pil. Biasanya keluhan yang muncul adalah keluhan somatik, kecemasan, serta kerentanan terhadap timbulnya stresor dari lingkungan (Toffol, 2011). Hampir seperempat wanita terbanyak ada pada kecamatan Banguntapan yaitu sebanyak 1.941 peserta, Sewon sebanyak 1.614 peserta, dan Kecamatan Kasihan sebanyak 997 peserta. Berdasarkan data Hasil Kegiatan Program Keluarga Berencana Nasional Kabupaten Bantul pada bulan Desember 2017 Wilayah Kerja Puskesmas Banguntapan I menempati urutan pertama yaitu sebesar 741 akseptor. Berdasarkan studi pendahuluan yang dilakukan di Wilayah Kerja Puskesmas Banguntapan I dari 12 akseptor pil yang diwawancarai, 7 orang ibu mengalami perubahan suasana hati sejak mengkonsumsi kontrasepsi pil, dengan rincian yaitu 2 orang ibu mengatakan lebih mudah gampang emosi padahal sedang tidak ada masalah, dan 4 orang mengalami perubahan perasaan menjadi tidak nyaman, dan 1 orang mengalami semangat menjalani aktifitas yang berkurang. Kondisi nyata saat ini, pengkajian mendalam mengenai masalah gambaran kepuasan pasien terhadap pelayanan kontrasepsi pil masih belum dilaksanakan. Pengkajian kesehatan mental pada pelayanan kontrasepsi pil belum dilaksanakan secara mendalam, misalnya pengkajian untuk skrining awal kesehatan mental calon akseptor pil, pemantauan kesehatan mental secara berkala pada akseptor pil, sehingga tingkat depresi akseptor pil belum dapat dievaluasi. Hal tersebut belum mampu terealisasi karena belum adanya Standar Operasional Prosedur mengenai pengkajian kesehatan mental yang mendalam di Fasilitas Pemberi Pelayanan Kontrasepsi.

\section{menyatakan bahwa mereka mengalami keluhan padaMETODE PENELITIAN}

perubahan suasana hati yang cenderung lebih tidak baik dari sebelum menggunakan kontrasepsi (Mulyani Mega, 2013).

Penelitian ini menggunakan desain survey analitic cross sectional. Populasi dalam penelitian ini adalah WHO memperkirakan bahwa depresi akan akseptor kontrasepsi pil di wilayah kerja Puskesmas
Banguntapan I. Teknik pengambilan sampel menjadi penyakit dengan beban global kedua manguntapan l. Teknik pengambilan sampel

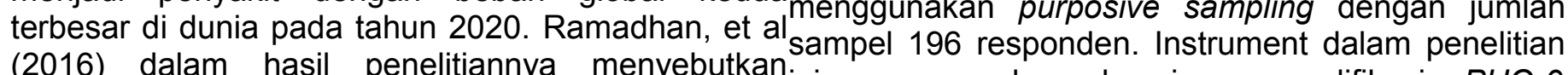
(2016) dalam hasil penelitiannya menyebutkan ini menggunakan kuesioner modifikasi PHQ-9 bahwa kontrasepsi pil memiliki paling banyak (Patient Health Questionare-9) yang mengacu pada kecenderungan depresi. Kontrasepsi Pil memiliki Diagnostic and Statistical Manual of Mental kandungan progestin sintetik $350 \mathrm{mg}$ norethindione, Disorders, Fourth Edition, Text Revision (DSM-IVdiikuti kontrasepsi suntik memiliki kadar progesterone $T R$ ). Uji bivariat dalam penelitian ini menggunakan 150 mg DMPA. Oinomen dan Masnian (2002) dalam uji statistik Chi square.

Nese Cinar (2012) melaporkan dari hasil studi yang telah dilakukan yaitu alasan beberapa wanitaHASIL DAN PEMBAHASAN menghentikan penggunaan kontrasepsi hormonal pilKarakteristik Akseptor Pil di Wilayah Kerja adalah karena perubahan suasana hati berupa Puskesmas Banguntapan I depresi. Depresi pada ibu akan menghasilkan gejala mental dan fisik yang mempengaruhi kualitas hidup Hasil karakteristik responden dapat dilihat dan produktivitasnya. Depresi dapat mengganggupada tabel berikut: 
Tabel 1 Karakteristik Akseptor Pil di Wilayah Kerja Puskesmas Banguntapan I

\begin{tabular}{|c|c|c|}
\hline Variabel & Frekuensi (f) & Prosentase (\%) \\
\hline \multicolumn{3}{|l|}{ Jenis Pil } \\
\hline Pil progestin & 41 & 20.9 \\
\hline Pil Kombinasi & 155 & 79.1 \\
\hline \multicolumn{3}{|l|}{ Usia } \\
\hline Usia risiko rendah & 73 & 37.2 \\
\hline Usia risiko tinggi & 123 & 62.8 \\
\hline \multicolumn{3}{|l|}{ Lama Pil } \\
\hline 6 bln-2 tahun & 101 & 51.5 \\
\hline$>2$ tahun & 95 & 48.5 \\
\hline \multicolumn{3}{|l|}{ Pendidikan } \\
\hline $\begin{array}{l}\text { Pendidikan Rendah } \\
\text { (SD\&SMP) }\end{array}$ & 71 & 36.2 \\
\hline $\begin{array}{l}\text { Pendidikan Tinggi (SMA\& } \\
\text { PT) }\end{array}$ & 125 & 63.8 \\
\hline \multicolumn{3}{|l|}{ Pekerjaan } \\
\hline Tidak Bekerja & 102 & 52.0 \\
\hline Bekerja & 94 & 48.0 \\
\hline \multicolumn{3}{|l|}{ Penghasilan } \\
\hline $\begin{array}{l}\text { Pendapatan < } \\
\text { Rp.1.527.150,- }\end{array}$ & 91 & 46.4 \\
\hline $\begin{array}{l}\text { Pendapatan lebih dari } \\
\text { Rp.1.527.150,- }\end{array}$ & 105 & 53.6 \\
\hline \multicolumn{3}{|l|}{$\begin{array}{l}\text { Tingkat kecenderungan } \\
\text { depresi }\end{array}$} \\
\hline Normal & 145 & 74.0 \\
\hline Depresi Ringan & 45 & 23.0 \\
\hline Depresi Sedang & 6 & 3.0 \\
\hline
\end{tabular}

Sumber: Data Primer, 2018

Hasil penelitian

tentang

karakteristik

\section{Hubungan Lama Penggunaan Kontrasepsi Pil Dengan Kejadian Depresi}

Hasil penelitian menunjukkan paling banyak responden akseptor kontrasepsi pil dengan tidak depresi dengan jangka lama penggunaan $\leq 2$ tahun berjumlah $82(41,83 \%)$ responden. Penguji hipotesis menunjukkan terdapat hubungan faktor lama penggunaan pil dengan tingkat kecenderungan depresi di Wilayah Kerja Puskesmas Banguntapan I dengan harga koefisien hubungan dengan $p$-value sebesar 0,018<0,05 dan OR 2,192.

Dalam penelitian ini responden yang menggunakan pil $\leq 2$ tahun lebih tidak beresiko untuk terjadi depresi. Hal ini dapat disebabkan karena lebih singkatnya rentang waktu lama penggunaan $\leq 2$ tahun mengakibatkan lebih rendahnya jumlah kandungan hormon yang dikonsumsi jika dibandingkan pada penggunaan kontrasepsi pil dengan waktu yang lebih lama yaitu $>2$ tahun. Hasil penelitian ini sesuai dengan penelitian Robert (2017) bahwa risiko untuk mengalami depresi dan memulai untuk mengkonsumsi obat anti depresi dimulai 3-6 bulan setelah penggunaan kontrasepsi hormonal.

Hasil penelitian ini sesuai dengan penelitian yang diterbitkan oleh Journal of the American Assosiation (JAMA) Psychiatry menunjukkan bahwa $23 \%$

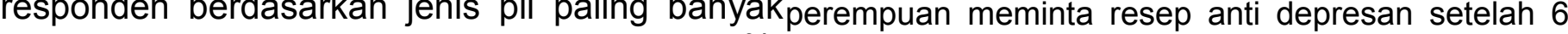
menggunakan pil kombinasi sebanyak 79,10\%.bulan menggunakan pil KB. $34 \%$ perempuan yang Berdasarkan usia akseptor pil kombinasi danmengkonsumsi pil progestin dilaporkan mengalami akseptor mini pil menunjukkan bahwa sebagiangejala depresi dan membutuhkan anti depresan. besar berusia risiko tinggi yaitu $64,52 \%$ danHasil penelitian ini sesuai dengan penelitian $56,10 \%$. Berdasarkan lama penggunaan, Noprisanti (2013) menunjukkan bahwa pada penggunaan pil kombinasi lebih banyak dengan penggunaan kontrasepsi hormonal lebih dari 2 tahun lama penggunaan $>2$ tahun $51,61 \%$, sedangkan dapat menyebabkan gangguan psikologis sebanyak akseptor mini pil paling banyak dengan lama $96,3 \%$ dan gangguan somatik sebanyak $77,3 \%$.

penggunaan $\leq 2$ tahun sebanyak $63,41 \%$ Pil akan menggantikan produksi normal estrogen pengesterone oleh ovarium. Adanya hormon Berdasarkan tingkat pendidikan akseptor pil tersebut akan menyebabkan gangguan perasaan kombinasi dan mini pil, paling banyak denganpada penggunan pil tersebut. Hasil penelitian ini pendidikan tinggi sebanyak $60,98 \%$ akseptorsesuai dengan dengan pendapat Schimeilpfering mini pil dan 64,52\% akseptor pil kombinasi.(2009) Estrogen dan progesterone telah ditunjukkan Berdasarkan status pekerjaan, akseptor minipiluntuk mempengaruhi neurotransmitter, lebih banyak dengan status bekerja 60,97\%, danneuroendokrin dan sistem sirkadian yang terlibat akseptor pil kombinasi lebih banyak dengandalam gangguan suasana perasaan.

status tidak bekerja $50,32 \%$. Berdasarkan status Dalam penelitian ini menemukan bahwa depresi sosial ekonomi akseptor pil kombinasi dan mini lebih banyak ditemukan pada akseptor pil kombinasi pil diketahui paling banyak memiliki penghasilan yang mengandung hormon estrogen dan il diketan progestin yang merupakan lebih dari UMR yaitu sebanyak $53,66 \%$ akseptor bentuk sintetis dari progesteron yang terdapat dalam mini pil dan 53,55\% akseptor pil kombinasi. Pada pil kombinasi yang dapat menurunkan tingkat variabel tingkat kecenderungan depresi padaserotonin dalam otak. Serotonin berperan untuk akseptor pil kombinasi dan mini pil paling banyakmempengaruhi mood/perasaan seseorang, dengan tidak depresi sebanyak 85,36\% akseptormempengaruhi keinginan, memunculkan rasa lapar, mini pil dan 70,96 akseptor pil kombinasi.

journal.umbjm.ac.id/index.php/midwiferyandreproduction mengantuk, mengatur suhu tubuh dan berperan penting dalam aktivitas memori dan proses 
pembelajaran (Yulianti, 2010). Progesteron bertanggung jawab atas hilangnya kelembaban pada

daerah vagina karena timbunan lemak yangRamadhan Ghuiranda, Alif Mardijana, Hairrudin. dihasilkan oleh progesteron tidak dapat menyerap air sehingga kelembaban menurun. Hal ini dapat mengakibatkan vagina menjadi kering sehingga menimbulkan rasa tidak nyaman saat bersenggama.

Depresi pada akseptor kontrasepsi hormonal dapat disebabkan karena stres yangRoberts Timothy A., Hansen Shana. (2017). berkepanjangan. Stres dapat terjadi karena Association of Hormonal Contraception with penurunan kepercayaan diri akibat berat badan yang bertambah secara cepat. Hormon estrogen menyebabkan retensi air dan oedem, sedangkanSani, progesteron mempermudah perubahan karbohidrat dan gula menjadi lemak dan merangsang nafsu makan serta menurunkan aktifitas fisik. Estrogen mempunyai efek pigmentasi yang menyebabkan bercak berwarna coklat, dan biasanya timbul di pipi dan dahi atas (Zumroatun, 2010).

Penelitian ini sejalan dengan penelitian SaniSkovlund CW, Kessing LV, Mørch LS, et al. (2017). (2014) yang menunjukkan hasil terdapat pengaruh lamanya penggunaan kontrasepsi hormonal terhadap tingkat depresi, hal ini diakibatkan berkurangnya tingkat serotonin dalam otak secara terus menerus. Fungsi serotonin adalah pengatur mood/perasaanSkovlund CW, Morch LS, Kessing LV, et al. (2016). seseorang. Sehingga semakin lama penggunaan alat kontrasepsi semakin berat depresi yang ditimbulkan.

\section{KESIMPULAN}

Ada hubungan yang signifikan antara lama penggunaan kontrasepsi pil dengan tingkat kecenderungan depresi di Wilayah Kerja Puskesmas Banguntapan I Tahun 2018.

\section{DAFTAR PUSTAKA}

Cinar N, Harmananci, Demir, and Yildiz. (2012). Thomson RL, Buckley JD, Lim SS, Noakes M, Clifton Effect of An Oral Contraceptive on Emotional Distress, Anxiety and Depression of Women with Polycystic Ovary Syndrome. Human Reproduction Journal, 27(6), 1840-1845.

Kemenkes RI. (2015). Profil Kesehatan RI. Jakarta: Kementerian Kesehatan Republik Indonesia.

National Anxiety and Depression Awareness Week. (2015). Artikel Ilmiah. Retrieved from: http://www.freedomfromfear.org/NationalAnxiety andDepressionAwarenessWeek.en.html.

National Institute of Mental Health. (2016). Depression.. Artikel IImiah.. Retrieved from: http://www.nimh.nih.gov/health/topics/depressio n/index.shtml

Oinonen KA, Mazmanian D. (2002). To what extentYonkers, Kimberly A. (2017). The Influence of Cyclic do oral contraceptives influence mood and Hormonal Contraception on Expression of

(2017). The Difference of Depression Tendency Level on User of Several Hormonal Contraception Types in Sumbersari Primary Health Care Jember. E-Journal Pustaka Depression in the Postpartum Period. Contraception Journal, 96(6), 446-452.

uriayu Primita, Alif, dan Kristianingrum Kontrasepsi Hormonal terhadap Tingkat Kecenderungan Depresi. Retrieved from: http://repository.unej.ac.id /bitstream/handle/123456789/68179/Nuriayu $\% 20$ Primita $\% 20$ Sani.pdf?sequence $=1$.

Increase in depression diagnoses and prescribed antidepressants among young girls, A national cohort study 2000-2013. Nordic Journal of Psychiatry, 71(5), 378-385.

Association of Hormonal Contraception With Depression. JAMA Psychiatry, 73(11), 11541162.

Sri Handayani. (2017). Mengapa Kasus Gangguan Jiwa di Yogyakarta Tinggi. Artikel Ilmiah. Retrieved http://www.republika.co.id/berita/ nasional/umum/17/07/20/otcmoo327-mengapakasus-gangguan-jiwa-di-yogyakarta-tinggi.

Sugiyono. (2012). Metode Penelitian Kuantitatif Kualitatif R\&D. Bandung: Alfabeta.

PM, Norman RJ, Brinkworth GD. (2010). Lifestyle Management improves quality of life and depression in overweight and obese women with polycystic ovary syndrome. Fertility and Sterility, 94(5), 1812-1816.

Toffol E, Heikinheimo O, Koponen P, Luoto R, Partonen T al. (2012). Hormonal contraception and mental health: results of a populationbased study. Human Reproduction Oxford, England, 26(11), 3085-3093.

Yonkers KA, Brown C, Pearlstein TB, Foegh $M$, Sampson-Landers C, Rapkin A. (2005). Efficacy of A New Low-Dose Oralcontraceptive with Drospirenone In Premenstrual Dysphoric Disorder. Obstetricts and Gynecology Journal,

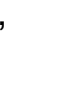

journal.umbjm.ac.id/index.php/midwiferyandreproduction 
Premenstrual Syndrome. Journal of Women's Health, 26(4), 321-32 8 